\title{
La esclava del cielo, Santa Engracia, una comedia olvidada de Andrés de Claramonte
}

\author{
Alejandro García Reidy \\ Universitat de València \\ Fecha de recepción: 12/02/2009, Fecha de publicación: 15/03/2009 \\ <URL: http://www.studiaaurea.com/articulo.php?id=94 >
}

\begin{abstract}
Resumen
El objetivo de este artículo es doble: en primer lugar, dilucidar la relación que existe entre la copia manuscrita que se conserva de una comedia titulada La esclava del cielo, Santa Engracia y la obra de este título que se menciona en diversos documentos del siglo Xvir relativos a las compañías de los autores Cristóbal Ortiz, Juan Bautista Valenciano y Juan Jerónimo Valenciano. En segundo lugar, analizar críticamente la atribución de La esclava del cielo, Santa Engracia al dramaturgo Andrés de Claramonte que figura en varios de estos documentos, valorando la validez de la información aportada en ellos y atendiendo a criterios de métrica y dramaturgia para establecer la autoría de la pieza. Como mostraré, el manuscrito conservado corresponde con la comedia del dramaturgo murciano que hasta la fecha se consideraba perdida.
\end{abstract}

Palabras clave.

Andrés de Claramonte. Obra teatral.

\begin{abstract}
La esclava del cielo, Santa Engracia, a forgotten play by Andrés de Claramonte

Two are the objectives of this paper: in the first place, to elucidate the relationship that exists between the manuscript copy that has been preserved of a play entitled La esclava del cielo, Santa Engracia and the play of the same title that is mentioned in several documents of the 17th Century related to the professional companies of the autores Cristóbal Ortiz, Juan Bautista Valenciano and Juan Jerónimo Valenciano. In the second place, to critically analyze the attribution of La esclava del cielo, Santa Engracia to the playwright Andrés de Claramonte that appears in several of these documents, both by assessing the validity of the information present in these documents and by taking into account metric and dramaturgical criteria in order to establish the authorship of the play. As I will prove, the preserved manuscript is the same play by the Murcian playwright that was considered lost until now.
\end{abstract}

Key words

Andrés de Claramonte. Dramatic corpus 
Al principio de la loa titulada Enigma de la mujer, ${ }^{1}$ incluida en El viaje entretenido, el representante y dramaturgo Agustín de Rojas Villandrando da cuenta de un encuentro ficticio con unos caballeros que acaban de asistir a la representación de una comedia, quienes discuten sobre la autoría de la obra y sus (de)méritos artísticos:

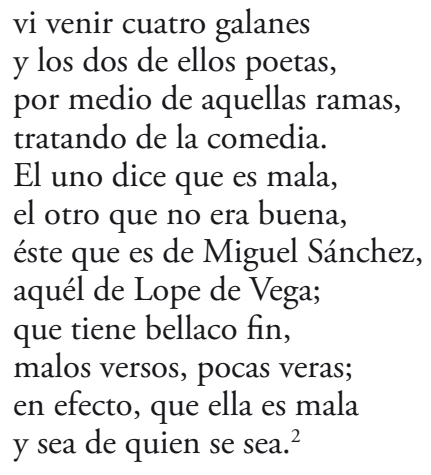

Esta breve referencia, circunstancial al tema central de la loa, supone un curioso testimonio de cómo la autoría de una comedia podía ser problemática incluso para el público del siglo Xvir que acudía con regularidad a las representaciones que tenían lugar en corrales y casas de comedias. Algunas cosas no cambian con el paso del tiempo: cuatro siglos más tarde nos seguimos preguntando acerca de la autoría de numerosas piezas escritas para el teatro comercial barroco.

En el caso de Andrés de Claramonte, un hombre ligado al teatro profesional durante más de veinte años en calidad de dramaturgo, representante y autor de compañía propia, las dificultades que ofrece la fijación de su corpus dramático (y la datación del mismo) han sido puestas de relieve en numerosas ocasiones por la crítica. Claramonte solamente publicó en vida dos de sus obras dramáticas: se trata de dos loas, tituladas La Asunción de la Virgen y Las calles de Sevilla, que vieron la luz en Sevilla en 1621. El grueso de su producción teatral, en cambio, ha llegado hasta nosotros bien en forma de manuscritos empleados por compañías profesionales, bien en forma de ediciones impresas publicadas en sueltas o como parte de volúmenes de comedias de dramaturgos varios; dos cauces de transmisión que sólo agudizan los problemas de la fijación de autoría, pues

1. El presente trabajo se ha beneficiado de mi participación en dos proyectos de investigación: el proyecto Las comedias y sus representantes. Base de datos de las comedias mencionadas en la documentación teatral (1540-1700), dirigido por Teresa Ferrer Valls (Universitat de València) y financiado por el Ministerio de Ciencia e Innovación (referencia FFI2008-00813) y por fondos FEDER, y el Diccionario de argumentos del teatro de Lope de Vega, dirigido por Joan Oleza Simó (Universitat de València) y financiado por el Ministerio de Ciencia y Tecnología (referencia HUM2006-09148) y por fondos FEDER.

2. Rojas Villandrando (1995: 231). 
a menudo los testimonios carecen de atribución (varios de los manuscritos) o presentan atribuciones poco fiables (las ediciones impresas).

Este panorama ha obligado a la crítica a abordar con cautela la tarea de delimitar y clarificar la nómina de obras dramáticas que salieron de la pluma de Claramonte, discriminando en lo posible las atribuciones fiables de las más dudosas. Ya Sturgis Leavitt, en la monografía que dedicó al dramaturgo murciano hace casi ochenta años, ${ }^{3}$ dio su parecer sobre algunas comedias que podían atribuirse a Claramonte, aunque han sido los estudios posteriores de Rodríguez López-Vázquez los que más ampliamente han abordado el problema del corpus teatral del murciano. ${ }^{4}$ La labor investigadora realizada hasta la fecha ha contribuido a arrojar bastante luz sobre la problemática bibliografía teatral de Claramonte, aunque todavía perviven puntos oscuros pendientes de un estudio más exhaustivo y concluyente.

Como resumen, podemos clasificar las obras relacionadas con Claramonte en tres categorías diferentes. Por un lado contamos con una veintena de obras que conforman el corpus dramático de Claramonte comúnmente aceptado por la fiabilidad de las atribuciones que figuran en los testimonios que nos han llegado y por rasgos de métrica y estilo. ${ }^{5}$ Por otro lado se encuentra un grupo relativamente amplio de comedias de autoría problemática, que algunos críticos han atribuido con más o menos reservas a Claramonte fundándose en atribuciones presentes en testimonios de la época o en similitudes temáticas y de estilo con las obras que son suyas con seguridad. ${ }^{6}$ Finalmente, existe también un grupo de comedias que se atribuyen a Claramonte en distintos documentos del siglo XVII vinculados a la actividad teatral de las compañías profesionales, comedias

3. Leavitt (1931: 55-81).

4. Véanse las reflexiones que ha dedicado a esta cuestión Rodríguez López-Vázquez (1987) en su estudio sobre el dramaturgo murciano y $E l$ burlador de Sevilla, así como en las introducciones a diversas ediciones de comedias de Claramonte (1984: 1-61; 1985: 1-64; 1991a: 1-43; 1991b: 13-133; 1993: 1-50; 2000: 1-108). Remito asimismo a las observaciones sobre el corpus dramático de Claramonte realizadas por $M^{a}$ del Carmen Hernández Valcárcel en su «Introducción biográfica y crítica» a Claramonte (1983: 9-128) y por Charles Ganelin en su «Introduction» a Claramonte (1987: 23-30).

5. Este grupo estaría formado, además de por las dos loas ya citadas, por la loa El juego del hombre, por dos autos sacramentales (El horno de Constantinopla y El dote del Rosario) y por las siguientes comedias: El ataúd para el vivo y el tálamo para el muerto, La católica princesa Leopolda, De Alcalá a Madrid, De lo vivo a lo pintado, Deste agua no beberé, El gran rey de los desiertos, San Onofre, El infante de Aragón, La infelice Dorotea, El nuevo rey Gallinato, El secreto en la mujer, El valiente negro en Flandes, El honrado con su sangre, El inobediente o la ciudad sin Dios, El Tao de San Antón, El mayor rey de los reyes, Púsoseme el sol, saliome la luna o Santa Teodora y San Carlos o Las dos columnas de Carlos. 6. La nómina de comedias que se han atribuido en algún momento a Claramonte es relativamente amplia. Entre éstas encontramos obras como De los méritos de amor, el secreto es el mayor, El infanzón de Illescas, La Estrella de Sevilla o Dineros son calidad, cuya atribución a Claramonte no siempre ha estado exenta de polémica. Para una aproximación general a este conjunto de comedias de atribución dudosa, remito a las observaciones de Rodríguez López-Vázquez en su "Introducción» a Claramonte (1991b: 126-130) y Urzáiz Tortajada (2002: 254-259). 
de las que sólo conocemos los títulos al no haber llegado hasta nosotros y que se consideran obras perdidas del murciano. ${ }^{7}$

La documentación de época ofrece, de hecho, una vía de investigación que, en algunos casos, puede conducir a la recuperación de obras inéditas de dramaturgos barrocos. Gracias al Diccionario biográfico de actores del teatro clásico español (DICAT), un proyecto dirigido por Teresa Ferrer Valls y que ha supuesto el tratamiento informatizado de trescientas fuentes con noticias sobre actores españoles de los siglos XVI y XVII, ${ }^{8}$ contamos con un instrumento que facilita enormemente la consulta y el cotejo de diferentes fuentes documentales y que supone un punto de partida fundamental para el estudio de noticias de representación de obras de diversos dramaturgos áureos, entre ellos Andrés de Claramonte. Valga como ejemplo el caso de la comedia hagiográfica titulada San Carlos, que ha llegado a nosotros en forma manuscrita y que hasta la fecha no se había relacionado con Andrés de Claramonte, pero que le pertenece, como se ha demostrado recientemente con la ayuda de la información recopilada en el DICAT. ${ }^{9}$

En el presente artículo quiero dar cuenta de una comedia que es atribuida a Andrés de Claramonte en dos documentos del siglo xviI y que se considera una obra perdida suya. Como mostraré a continuación, diversos investigadores han relacionado esta comedia mencionada en las fuentes documentales con un manuscrito que se conserva en la Biblioteca Nacional de Espańa, sin que dicha identificación haya sido nunca corroborada o rechazada. La comedia en cuestión se titula La esclava del cielo, Santa Engracia y, gracias al citado DICAT, es posible rastrear cómo una obra con este título pasó en la década de 1620 del repertorio de la compañía de Cristóbal Ortiz de Villazán a la de Juan Bautista Valenciano, primero, y a la de su hermano Juan Jerónimo Valenciano, más tarde. ${ }^{10}$ El objetivo de este artículo es, por consiguiente, aclarar la posible relación entre el manuscrito existente y la comedia mencionada en la documentación de la época, y confirmar la atribución de esta obra a Andrés de Claramonte.

7. Rodríguez López-Vázquez da cuenta de algunas de estas comedias en el catálogo bibliográfico que cierra la «Introducción» a Claramonte (1991b: 126-130). El mejor lugar para encontrar un listado completo de estas comedias es el ya mencionado catálogo de Urzáiz Tortajada (2002: 254-259).
8. Ferrer Valls (dir.) (2008). Todas las noticias de actores que menciono a lo largo de este estudio están tomadas de esta base de datos. 9. Véase García Reidy (2008a y 2008b).

10. Para un estudio de las trayectorias profesionales y biográficas de los hermanos Valenciano, remito a Ferrer Valls (2002 y 2008). 


\section{Una comedia en el circuito teatral barroco}

La primera noticia referida a La esclava del cielo con la que contamos es una obligación, fechada en Sevilla el 6 de julio de 1620, por la que Juan Bautista Valenciano y su mujer, Manuela Enríquez, como principales otorgantes, y Juan Jerónimo Valenciano, como su fiador, todos ellos representantes en la compañía que hasta entonces había dirigido Cristóbal Ortiz de Villazán, se comprometían a pagar a este autor de comedias 4.800 reales, 3.000 de los cuales correspondían a un préstamo hecho por Ortiz a Juan Bautista Valenciano y su mujer, Manuela Enríquez, mientras que los otros 1.800 reales eran el resto de los 3.660 reales en que Ortiz les había vendido un total de dieciocho comedias. ${ }^{11}$ La razón de esta venta de comedias radica en el hecho de que ese mismo 6 de julio Cristóbal Ortiz había cedido su licencia de autor de comedias otorgada por el Consejo Real al mencionado Juan Bautista Valenciano por espacio de siete meses, hasta el Martes de Carnaval de 1621 (es decir, el final de la temporada teatral), alegando Ortiz que debía marcharse a Madrid "por negocios que me importan" y que le obligaban a desvincularse temporalmente de la dirección de su compañía. ${ }^{12}$

Juan Bautista Valenciano, ahora al frente de la formación que durante años había encabezado Cristóbal Ortiz y en la que él mismo había estado trabajando, se veía en la situación de tener que comprar estas comedias que Ortiz tenía en su posesión para disponer rápidamente de un repertorio mínimo con el que asegurar la inmediata continuidad de las representaciones que tenía contratadas la compañía, al menos hasta que pudiera hacerse por su cuenta con nuevas obras con las que conformar su propio repertorio. La obligación no sólo da cuenta de los títulos de las dieciocho comedias vendidas por Ortiz a Juan Bautista Valenciano, sino que en ella se nombra también a los dramaturgos que las compusieron, algo no siempre habitual en la documentación de la época. Junto con obras atribuidas a Lope de Vega, Guillén de Castro o Mira de Amescua encontramos, como última de las nombradas, una comedia titulada La esclava del cielo y atribuida a "Claramonte». Además, en la citada obligación Ortiz afirmó que las comedias que entregaba a Juan Bautista Valenciano eran originales, compradas directamente a los poetas que las habían escrito: «las comedias que ansí le entrego son las mesmas originales que las personas que las compusieron me entregaron». ${ }^{13}$ Sobre esta declaración volveré más adelante.

Pese a que en la escritura del 6 de julio de 1620 Cristóbal Ortiz cedió sus derechos como autor de título hasta el final de la temporada teatral de 1620-1621, lo cierto es que, cuando volvió a los escenarios tras atender a sus "negocios», lo hizo en calidad de actor, pues en la primavera de 1621 figuraba, junto con su mujer, en la lista de los miembros de la compañía que el autor Alonso de Olmedo

11. Reyes Peña (1997).

12. Reyes Peńa y Bolaños Donoso (1992: 117).
13. Reyes Peńa (1997: 462). Modernizo la ortografía del pasaje citado. 
y Tofiño presentó a los organizadores de las fiestas del Corpus de Madrid. ${ }^{14}$ Juan Bautista Valenciano, por su parte, seguía en tierras andaluzas al frente de su compañía, aunque mantenía el contacto directo con Cristóbal Ortiz. En primer lugar, porque todavía le adeudaba dinero: el 28 de mayo de 1621 Juan Bautista Valenciano, su mujer y su hermano Juan Jerónimo Valenciano firmaron en Sevilla una obligación por la que se comprometían a pagar los 4.800 reales que debían a Ortiz por la escritura del 6 de julio del ańo anterior. ${ }^{15}$ En segundo lugar, porque Juan Bautista aprovechó la presencia en Madrid de Ortiz para nombrarlo procurador suyo, junto con el barbero madrileño Andrés Hernández. Juan Bautista otorgó el poder en Sevilla el 1 de junio y en él autorizó a Ortiz no sólo para que contratara representaciones para su compañía en los lugares y con las condiciones que estimara convenientes, sino también para que pudiera impedir la representación de cualquiera de las comedias que formaban parte de su repertorio, especialmente de tres de ellas: Querer su propia desdicha, Mirad a quién alabáis (las dos atribuidas a Lope de Vega en la escritura de compraventa de 1620) y Santa Engracia, así como del resto de obras que había adquirido a Ortiz en $1620 .{ }^{16} \mathrm{La}$ comedia La esclava del cielo, mencionada en este poder con el título alternativo de Santa Engracia, seguía, pues, en poder de Juan Bautista Valenciano a mediados de 1621, y el hecho de que éste la mencionara expresamente entre las comedias cuya representación por otras compañías Ortiz debía impedir es un significativo indicio de que la pieza formaba parte del repertorio activo de su compañía y de que mantenía su valor comercial en esas fechas.

Juan Bautista Valenciano seguiría al frente de su propia formación hasta febrero de 1624, cuando murió asesinado en Madrid, quizá a causa de alguna reyerta. Su hermano, Juan Jerónimo Valenciano, llevaba aproximadamente un año al frente de compañía propia cuando esto sucedió y aparentemente tomó el relevo de la formación de su hermano. Manuela Enríquez, viuda de Juan Bautista, se asoció entonces con su cunado, aportando las comedias que formaban parte del repertorio de su difunto esposo. Así, el 5 de marzo de 1624 Juan Jerónimo y

14. Shergold y Varey (1958: 37).

15. Rodríguez Marín (1914: 342). Aunque Rodríguez Marín fechó este documento el 4 de junio, Reyes Peña (1997: 469) señala que la fecha correcta es la del 28 de mayo.

16. Rodríguez Marín (1914: 342). De nuevo, Rodríguez Marín se equivocó al fechar el documento el 4 de mayo, como ha indicado Mercedes de los Reyes (1997: 469). Reyes y Bolaños (1992: 117-118), a su vez, afirman que la comedia se menciona con el título $L a$ esclava del Cielo, Santa Engracia en un poder que Juan Bautista Valenciano otorgó el 1 de mayo de 1621 en Sevilla a favor de un vecino de Portugal para que contratara su ida a Lisboa para representar de forma alterna en los dos teatros de la ciudad, pero no ofrecen más detalles ni transcriben el documento o, al menos, la parte donde supuestamente se cita la comedia. Rodríguez Marín (1914: 342), que fue el primero en dar cuenta de este poder, datándolo por error el 1 de junio, nada dice acerca de la mención del título de la comedia. ¿Puede tratarse acaso de una confusión de Reyes y Bolańos con el poder que Juan Bautista otorgó el 1 de junio de ese mismo año, donde sí que se menciona el título de la obra, como acabamos de ver? 
Manuela Enríquez otorgaron en Madrid un poder a favor de Francisco del Encinar para que concertara contratos, cobrase deudas y pudiese impedir que otras compañías representasen diversas comedias que habían sido adquiridas por los otorgantes del poder y por Juan Bautista Valenciano. ${ }^{17}$ Manuela Enríquez siguió en la formación de su cuñado hasta al menos 1628, pues tenemos documentada su presencia en la formación en 1625 y de nuevo en $1628 .^{18}$

Es precisamente en este último año cuando volvemos a documentar la comedia de La esclava del cielo, Santa Engracia. El 14 de junio se elaboró para el clavario del Hospital General de Valencia una memoria de las prendas y comedias que Juan Jerónimo Valenciano había dejado al Hospital como garantía de un préstamo que el clavario le había hecho a él y a Manuela Enríquez. ${ }^{19}$ El documento no ofrece los títulos de las comedias, pero dos meses más tarde, el 9 de agosto, el clavario del Hospital General reconoció tener en depósito las ropas y comedias que Juan Jerónimo le había dejado como garantía del préstamo y elaboró un inventario detallado de todos los bienes. De entre los más de sesenta títulos de comedias que se incluyen en este documento (muchos con atribuciones de los dramaturgos que las habían escrito), quince coinciden con las obras vendidas por Cristóbal Ortiz a Juan Bautista Valenciano en julio de 1620, como ha seña lado Mercedes de los Reyes; ${ }^{20}$ esto supone una prueba concluyente de que este repertorio seguía prácticamente por entero en manos de Manuela Enríquez y su cuńado a la altura del verano de 1628. En este listado de comedias encontramos, entre las obras que se atribuyen a Claramonte, La esclava del cielo. ${ }^{21}$

17. Bolaños Donoso (2006: 84-85). En este poder se ofrecen los títulos de veintiuna comedias en posesión de Juan Jerónimo Valenciano y Manuela Enríquez, con atribuciones de los dramaturgos responsables de las piezas. Entre ellas figuran tres comedias atribuidas a Andrés de Claramonte que no han llegado hasta nosotros: Santa Cecilia, La capitana del cielo y $L a$ fuerza contra fuerza.

18. Sobre la pertenencia de Manuela Enríquez a la compañía de Juan Jerónimo Valenciano durante 1625, véase Granja (1991). Mérimée (1913: 194-195), por su parte, dio cuenta de la presencia de una compañía dirigida por un autor llamado Juan Bautista 'el Valenciano' en Valencia en julio de 1627, formación a la que identificó con la de Juan Bautista Valenciano. Según dicho investigador, la compañía habría seguido representando tras la muerte de su director y fue tras esta presencia fracasada en Valencia cuando Manuela Enríquez se asoció con Juan Jerónimo Valenciano, aportando entonces el repertorio de su difunto esposo. Sin embargo, la documentación demuestra que Manuel Enríquez se integró en la compañía de su cuñado inmediatamente después de fallecer su marido, como ya he señalado. Gracias al $D I-$ $C A T$ sabemos que la compañía documentada por Mérimée en la ciudad del Turia en el verano de 1627 era probablemente la dirigida por un autor de segunda fila, quien tomó el nombre artístico de Juan Bautista Valenciano para tratar de aprovechar la fama del difunto actor $y$ autor. Véase Ferrer Valls (dir.) (2008).

19. Esquerdo Sivera (1978: 458-459).

20. Reyes Peña (1997: 464-465).

21. Mérimée (1913: 175-178). En el listado ofrecido por el investigador francés se atribuyen otras trece comedias a Andrés de Claramonte. Esquerdo (1975: 434-436), al dar cuenta del mismo documento, incluyó una comedia adicional entre las obras atribuidas al murciano. Sin embargo, como comentaré más adelante, las atribuciones presentes en este documento no son siempre fiables y deben tomarse con cautela. 
Éstos son los datos que la documentación teatral ofrece acerca de una comedia, La esclava del cielo, Santa Engracia, que aparece atribuida a Andrés de Claramonte tanto en 1620 como en 1628. Sin embargo, este título apenas es mencionado en los estudios más actuales que han abordado la producción teatral del dramaturgo murciano. No figura, por ejemplo, en la útil «Bibliografía comentada de Andrés de Claramonte» que Rodríguez López-Vázquez incluye al final de su estudio introductorio a la edición de La Estrella de Sevilla, ${ }^{22}$ aunque dicho investigador sí que menciona la obra en la introducción de otra reciente edición, donde alude al citado inventario de $1628 .{ }^{23}$ Héctor Urzáiz, por su parte, da cuenta en su catálogo teatral de la existencia de una comedia de este título atribuida a Andrés de Claramonte en la documentación valenciana, sin ofrecer más detalles ni mencionar que exista testimonio alguno de la obra. ${ }^{24}$ Parecería, por lo tanto, que nos encontramos ante un ejemplo más de una comedia de la que sólo hemos preservado el título por haberse citado en algunos documentos del siglo XviI, pero que no ha llegado hasta nosotros. No obstante, en el caso de La esclava del cielo, Santa Engracia no nos encontramos ante una comedia perdida, sino ante una obra que ha sido olvidada por la crítica, pues varios investigadores han llamado la atención sobre la existencia de una copia manuscrita de una comedia titulada precisamente La esclava del cielo, Santa Engracia, sin que su contenido se haya estudiado hasta la fecha. Como mostraré a continuación, este manuscrito está estrechamente vinculado a las noticias de las que acabo de dar cuenta.

22. Véase la «Introducción» de Rodríguez López-Vázquez a Claramonte (1991b: 126-130). 23. Véase la «Introducción» de Rodríguez López-Vázquez a Claramonte (2008: 15).

24. Urzáiz Tortajada (2002: 256). Urzáiz toma la información del catálogo de títulos presentes en la documentación teatral valenciana elaborado por Esquerdo (1979). También incluye en el listado de obras anónimas de su catálogo una comedia con el mismo título, La esclava del cielo, Santa Engracia, de la que afirma que fue representada en Sevilla, y remite al manuscrito
Ms. 15705 de la Biblioteca Nacional de Madrid (como enseguida se verá, ésta y la de Claramonte son en realidad la misma obra). Menciona asimismo que Sor Violante do Ceo escribió una comedia titulada Santa Engracia, comedia a la que también se refieren otras fuentes. Por último, cita Urzáiz un estudio de Miguel Martínez Aguilar (1996) en el que supuestamente se da cuenta de una edición de La esclava del cielo de 1619 , pero en el citado trabajo nada se dice sobre esta supuesta impresión, dato que parece deberse a una confusión de Urzáiz. 


\section{El Ms. 15705 de la BNE y la comedia La esclava del cielo}

El manuscrito en cuestión se conserva actualmente en la Biblioteca Nacional de Espańa con la signatura Ms. 15705, biblioteca a la que llegó en 1886 procedente de la colección del Duque de Osuna. ${ }^{25} \mathrm{El}$ manuscrito presenta un tamaño corriente de $210 \times 150 \mathrm{~mm}$. y está formado por cincuenta y seis folios — con numeración moderna a lápiz- encuadernados en pergamino; el texto está copiado por dos manos en letra del siglo xvir. El ejemplar incluye intervenciones que nos indican que fue empleado por actores profesionales para la representación: además de encontrar versos tachados y pasajes enjaulados a lo largo de todo el texto, en el vuelto de la encuadernación hay algunas anotaciones vinculadas a la contabilidad de una compañía, en concreto pagos hechos a actores de la formación y por materiales necesarios para una puesta en escena. A esto hay que añadir la presencia en el manuscrito de dos licencias de representación: la más temprana se encuentra al final del vuelto del último folio, en el espacio en blanco que queda tras el final del texto de la comedia, y está firmada por el licenciado Juan de Estrada en Sevilla el 4 de noviembre de 1619. Esta licencia está confirmada por el provisor de Sevilla en el vuelto del folio 37, un folio en blanco que queda entre las jornadas segunda y tercera. La segunda licencia se encuentra en el vuelto del folio 19, entre la primera y la segunda jornada, y está firmada en Granada en 1620 por don Francisco Martínez de Rueda. Por desgracia, el folio está dañado y es imposible saber el mes en el que se otorgó la licencia, aunque todavía es legible que se hizo en un día 13.

Como he señalado, este manuscrito teatral no es del todo desconocido para los investigadores del teatro áureo. Ya Sánchez-Arjona, al recopilar noticias teatrales de Sevilla acaecidas en el año 1619, dio cuenta de las dos licencias contenidas en este manuscrito y afirmó lo siguiente en relación con la autoría de la pieza: «No se sabe quién fuera el autor de esta comedia, que pudiera muy bien ser la que, escrita por Sor Violante do Ceo, lleva el título de Santa Engracia, y se había representado este mismo año en Lisboa ante Felipe III». ${ }^{26}$ Mérimée, a su vez, fue el primero en vincular este manuscrito con noticias procedentes de la documentación teatral. Al publicar el repertorio de 1628 de Juan Jerónimo Valenciano, sugirió la posibilidad de que la comedia La esclava del cielo allí mencionada como obra de Claramonte pudiera ser la misma que la comedia conservada en la Biblioteca Nacional. ${ }^{27}$ Por su parte, en un artículo publicado en 1992, Reyes y Bolaños rechazaron la posibilidad de que la comedia manuscrita La esclava del cielo fuera la comedia de Santa Engracia escrita por Sor Violante de Ceo y supusieron en cambio que estaba vinculada con la venta del repertorio

25. Paz y Melia (1934: I, 192).

26. Sánchez-Arjona (1898: 210). Por el momento no tenemos noticia de la pervivencia de ningún testimonio de la comedia de Sor Violante do Ceo.

27. Mérimée (1913: 178). 
de comedias entre Cristóbal Ortiz y Juan Bautista Valenciano que tuvo lugar en 1620 , aunque consideraron que se trata de una comedia «de autor desconocido». ${ }^{28}$ Pese a estas indicaciones, ningún investigador ha estudiado hasta la fecha el citado Ms. 15705 de la Biblioteca Nacional para determinar su exacta relación con las noticias contenidas en la documentación de la época referentes a la comedia La esclava del cielo atribuida a Andrés de Claramonte.

En primer lugar, es necesario clarificar si el manuscrito de la comedia de $L a$ esclava del cielo, Santa Engracia preservado en la Biblioteca Nacional está relacionado con la obra de título casi idéntico que pasó por los repertorios de Cristóbal Ortiz, Juan Bautista Valenciano y Juan Jerónimo Valenciano entre 1619 y 1628. El indicio más sólido se encuentra en las anotaciones presentes en el vuelto de la encuadernación del manuscrito. Se trata de dos listados de pagos hechos probablemente con motivo de una representación, pues al lado de entradas como «chirimías», "apariencias», "alamares» o "al carp[inter] o» se consignan cifras que corresponderían a pagos realizados en reales. Entre estas anotaciones (algunas de muy difícil lectura) es posible distinguir los nombres de algunos actores, junto con lo que parece ser el salario que recibieron por su participación en una representación: Fadrique (quien recibió un pago de 20 reales), Cosme (quien recibió un pago de 12 reales) y Narváez (quien recibió un pago de 10 reales y medio). Gracias a la información recogida en el DICAT, me parece que se puede identificar estos tres nombres con los representantes Fadrique de Montalbo Vaca, Cosme Pérez e Íñigo de Narváez. ${ }^{29}$

Por un lado, los tres figuran en la lista de integrantes de la compañía que Juan Bautista Valenciano presentó en la primavera de 1621 para poder participar en la representación de autos sacramentales de las fiestas del Corpus de Sevilla de ese año. ${ }^{30}$ Por otro lado, también aparecen en los repartos presentes en tres manuscritos dramáticos diferentes, repartos que se han vinculado con la compañía de Juan Bautista Valenciano. Se trata de los repartos que figuran en el manuscrito autógrafo de El desdén vengado, de Lope de Vega, que corresponde a la compañía de Juan Bautista Valenciano, como ya indicó Rennert, ${ }^{31}$ y al que acompaña una licencia de representación fechada en Lisboa el 21 de marzo de 1622; $; 2$ en La nueva victoria de don Gonzalo de Córdoba, también de Lope de Vega, reparto que igualmente pertenece a la compañía de Juan Bautista Valenciano, como también señaló Rennert, ${ }^{33}$ y al que acompaña una licencia fechada en Madrid el 21 de octubre de 1622; y, por último, en un manuscrito de La infelice Dorotea, de Andrés de Claramonte, escrita para la compañía de Juan Bautista Valenciano en 1620, según documenta una anotación presente en el encabe-

28. Reyes Peña y Bolaños Donoso (1992: 117).

29. Ferrer Valls (dir.) (2008).

30. Sentaurens (1984: 1242).

31. Rennert (1909: 369).

32. El manuscrito incluye también una licencia fechada en 1617, probablemente relacionada con una representación a cargo de la compañía de Cristóbal Ortiz, ya que figura entre las comedias que éste vendió a Juan Bautista en 1620. 33. Rennert (1909: 371). 
zamiento del manuscrito. Este manuscrito incluye dos licencias, fechadas en diciembre de 1621 y noviembre de $1622 .{ }^{34}$ Un actor llamado Fadrique, al que se ha identificado con Fadrique de Montalbo Vaca, ${ }^{35}$ aparece en los tres repartos; un actor llamado Cosme, al que se ha identificado con Cosme Pérez, figura en los repartos de El desdén vengado y La nueva victoria de don Gonzalo de Córdoba; mientras que un actor llamado Narváez, al que se ha identificado con Ínigo de Narváez, figura en el reparto de La nueva victoria de don Gonzalo de Córdoba. A la vista de las noticias que nos proporciona el listado de la compañía de Juan Bautista Valenciano para el Corpus sevillano de 1621 y los repartos y licencias de representación de estas tres comedias, estos tres actores formaron parte de la compañía de Juan Bautista Valenciano en torno a los años 1621-1622.

$\mathrm{Si}$ mis identificaciones son correctas en relación con las anotaciones hechas al comienzo del Ms. 15705 de la Biblioteca Nacional, éste habría formado parte del repertorio de la compañía de Juan Bautista Valenciano al menos hacia 1621-1622, cuando Fadrique de Montalbo Vaca, Cosme Pérez e Íñigo de Narváez pertenecían a su formación. Este hecho invita a identificar el manuscrito conservado con la comedia titulada La esclava del cielo (o Santa Engracia) que se menciona en la citada documentación de la época, ya que tanto el título como las fechas encajan a la perfección. Además, el que el manuscrito conserve una licencia de representación de finales de 1619, cuando el manuscrito todavía no estaba en poder de Juan Bautista Valenciano, indica que el manuscrito precede al traslado de titularidad que tuvo lugar entre Cristóbal Ortiz y Juan Bautista en el verano de 1620 , lo que apuntaría a su vez al hecho de que se trata del manuscrito que Ortiz vendió a su compañero y no de una copia sacada con posterioridad a la venta. Los datos proporcionados por los documentos notariales se corresponden así con la información que ofrece la propia materialidad del manuscrito en cuanto artefacto empleado por compañías de actores profesionales.

Ahora bien, las dos licencias conservadas en el manuscrito presentan algunas dificultades. Recordemos que la licencia más temprana está fechada en Sevilla el 19 de noviembre de 1619, cuando el manuscrito, en principio, formaría parte del repertorio de Cristóbal Ortiz. Las noticias recogidas en el DICAT documentan a la compañía de Ortiz en Madrid desde enero hasta mediados de mayo de ese año, cuando se desplazó a Sevilla para representar en las fiestas del Corpus (que se celebró el 30 de mayo). A partir de entonces hay una laguna que abarca prácticamente un año, pues no se vuelve a documentar positivamente la actividad profesional de su compañía hasta principios de mayo de 1620, cuando Ortiz estaba de nuevo en Sevilla preparándose para representar en las fiestas del Corpus de ese año. En principio, este silencio documental relativo a la segunda mitad de 1619 sería compatible con la licencia sevillana de noviembre, la cual

34. Idem: 370.

35. Todas las identificaciones provienen del ya citado DICAT. Véase Ferrer Valls (dir.) (2008). 
constataría la presencia de la compañía de Ortiz en la capital hispalense en ese mes. No obstante, el 17 de marzo de 1619 Cristóbal Ortiz se había concertado en Madrid con un apoderado del Hospital Real de Todos los Santos de Lisboa para representar con su compañía en esta ciudad durante los meses de octubre y noviembre de este año. ${ }^{36}$ Este apoderado firmó ese mismo día otra escritura con el autor de comedias Pedro Cebrián para que éste tomara el relevo de Ortiz en las representaciones en el Patio de las Arcas de Lisboa a partir del 1 de diciembre y representara allí hasta el final de la temporada teatral. ${ }^{37}$ Mercedes de los Reyes y Piedad Bolaños, al estudiar la presencia de compañías españolas en Lisboa en la primera mitad del siglo XVII, no hallaron documentación lisboeta que confirmara la estancia en esta ciudad de Ortiz en los meses de octubre y noviembre de 1619, aunque las investigadoras dieron por supuesto que tanto este autor como Cebrián cumplieron sus respectivos contratos. ${ }^{38}$ Parece difícil conjugar la presencia de Ortiz en Lisboa en noviembre de 1619 con la licencia sevillana del mismo mes incluida en el manuscrito de La esclava del cielo, Santa Engracia. La licencia de representación fechada en Granada en 1620 no ayuda a aclarar esta contradicción, en parte por la imposibilidad de saber el mes en el que se otorgó. De estar el manuscrito en posesión de Cristóbal Ortiz, éste pudo acudir a representar a Granada en la primera mitad de 1620, antes de regresar a Sevilla para participar en las fiestas del Corpus en mayo. Esta segunda licencia también pudo otorgarse cuando el manuscrito ya estaba en manos de Juan Bautista Valenciano, pues no sabemos dónde representó con su compañía entre finales de julio de 1620 (cuando seguía en Sevilla) y finales de diciembre (cuando comenzó a representar en Córdoba). ${ }^{39}$

¿Cómo explicar estas discrepancias? Me parece determinante el hecho de que el manuscrito estuviera en manos de Juan Bautista Valenciano hacia 16211622, como he mostrado, lo que concuerda con las noticias que nos aporta la documentación notarial. Todo ello me inclina a pensar que el manuscrito conservado en la Biblioteca Nacional es el mismo que formó parte del repertorio de Cristóbal Ortiz y que éste vendió a Juan Bautista Valenciano en julio de 1620, $y$, por consiguiente, la misma comedia que aparece en la documentación notarial antes mencionada como obra de Andrés de Claramonte. De ser cierta mi suposición respecto a la pertenencia del manuscrito Ms. 15075 de la Biblioteca Nacional a los repertorios de Cristóbal Ortiz y, posteriormente, de Juan Bautista Valenciano, Ortiz tuvo que encontrarse a finales de noviembre de 1619 en Sevilla y no en Lisboa, pese a lo pactado con el representante del Hospital de Todos los Santos de Lisboa en marzo de este ańo, tal y como se deriva de la existencia de la licencia de representación sevillana. Dado que en ocasiones las compañías

36. Pérez Pastor (1901: 177-178).

37. Idem: 178 .

38. Reyes Peña y Bolaños Donoso (1992: 115116).
39. Para la trayectoria profesional de la compañía de Cristóbal Ortiz y Juan Bautista Valenciano por estas fechas, remito al citado DICAT. 
no siempre cumplían al pie de la letra las fechas establecidas en los contratos firmados, retrasando a veces su llegada a la ciudad donde debían representar o adelantando su partida sobre la fecha prevista por cuestiones varias del oficio, es posible que la compañía de Ortiz adelantara su regreso a Sevilla desde Lisboa (si es que llegó a representar en dicha ciudad) y estuviera en la capital hispalense hacia mediados de noviembre de 1619, cuando llevaría a cabo las gestiones burocráticas necesarias para representar La esclava del cielo, Santa Engracia en la ciudad. A falta de más datos que aclaren definitivamente esta cuestión, me parece que es la hipótesis que mejor explicaría las aparentes discrepancias entre la información que proporciona la documentación de la época y la que aporta la licencia de representación de 1619. En todo caso, me parece que la información de la que disponemos permite establecer con suficiente seguridad la identificación del manuscrito Ms. 15705 con el que formó parte sucesivamente de los repertorios de las compañías de Cristóbal Ortiz, Juan Bautista Valenciano y Juan Jerónimo Valenciano entre 1619 y 1628. 


\section{Andrés de Claramonte, autor de La esclava del cielo, Santa Engracia}

Una vez establecida la relación entre el manuscrito conservado en la Biblioteca $\mathrm{Na}$ cional de España y las referencias presentes en la documentación de la época a una comedia titulada La esclava del cielo, hay que abordar el problema de la atribución de La esclava del cielo, Santa Engracia a Andrés de Claramonte..$^{40}$ En primer lugar, debemos preguntarnos por la fiabilidad de la atribución hecha en la documentación, particularmente en la escritura de 1620 por ser ésta la más temprana en mencionar a Andrés de Claramonte como autor de La esclava del cielo. Valga como ejemplo de la cautela que debe adoptarse cuando se manejan atribuciones hechas en documentos de esta naturaleza el hecho de que cuatro de las comedias presentes tanto en el listado de comedias que Ortiz vendió a Juan Bautista Valenciano en 1620 como en el listado valenciano de 1628 presentan divergencias en las atribur ciones, como ha señalado Mercedes de los Reyes, aunque no afectan a La esclava del cielo. ${ }^{41}$ De las dieciocho comedias que Ortiz vendió a Juan Bautista Valenciano en 1620, la mitad no se ha conservado, por lo que no es posible determinar la validez de las atribuciones; de las otras nueve, una es La esclava del cielo y el resto son obras atribuidas a Lope de Vega: seis de ellas son comedias auténticas del Fénix ${ }^{42}$ mientras que las otras dos presentan algunos problemas de atribución. ${ }^{43}$ Por estadística, la atribución a Andrés de Claramonte de La esclava del cielo, Santa Engracia en este documento es verosímil, aunque no es, en absoluto, definitiva. El que la comedia siguiera figurando a nombre de Claramonte en el mencionado documento de 1628 (el cual, como acabo de señalar, ofrece divergencias en otras atribuciones) es otro indicio a favor de la validez de esta atribución: pese al paso de los años, Manuela Enríquez y Juan Jerónimo Valenciano seguían relacionando esta comedia con el dramaturgo murciano.

40. Salvo el ya citado catálogo de Urzáiz, el resto de principales catálogos teatrales nada dicen sobre la autoría de esta comedia. De hecho, en el catálogo de Medel del Castillo recopilado por Mill (1929: 182 y 242) encontramos lo que parecen ser dos entradas diferenciadas para la misma comedia: por un lado figura la comedia Esclava del cielo y, por otro, se da entrada diferenciada a Santa Engracia, y esclava del cielo, sin atribución alguna en ambos casos. Barrera y Leirado (1969: 547), por su parte, consultó el manuscrito cuando formó parte de la colección del Duque de Osuna y, en la entrada correspondiente de su catálogo, atribuyó la obra simplemente a "Un ingenio». Paz y Melia (1934: I, 192) dio cuenta de que con el título de Santa Engracia escribieron comedias Anaya y Espinosa, Francisco Bueno y Sor Violante do Ceo. 41. Reyes Peña (1997: 465). El mismo Méri- mée (1913: 175-178), al dar a conocer el documento de 1628, percibió los problemas de varias atribuciones y trató de subsanar los que localizó.

42. Se trata de Querer la propia desdicha, Mirad a quién alabáis, Lo que pasa en una tarde, La esclava de su hijo, El valor de las mujeres y $E l$ desdén vengado.

43. Una de estas comedias, Don Diego de noche, se considera comúnmente de Francisco de Rojas Zorrilla, aunque esta atribución también ha sido cuestionada: véase Urzáiz Tortajada (2002: 567). La segunda comedia, La industria contra el poder, presenta un título idéntico con el que también se conoce la comedia de Calderón de la Barca Amor, honor y poder. Sin embargo, se trata obviamente de obras distintas, pues la de Calderón no se estrenaría hasta junio de 1623. 
Con todo, existe un ligero problema con la escritura de 1620: frente a la afir mación hecha por Cristóbal Ortiz al vender a Juan Bautista Valenciano dieciocho comedias de su repertorio de que le entregaba «originales» adquiridos directamente de los dramaturgos, el manuscrito de La esclava del cielo, Santa Engracia no es un original en el sentido de "original autógrafo del dramaturgo", sino una copia en limpio hecha por copistas. Así lo muestra la ausencia de correcciones in itinere, la distribución de algunas tiradas en romance en forma de columnas colocadas simétricamente hasta la mitad de un folio (lo que implica que el copista sabía de antemano cuántos versos ocuparía cada columna) y, sobre todo, la presencia de dos manos distintas en el manuscrito: aunque un copista realizó la mayor parte de la labor, una segunda mano intervino en gran parte o en la totalidad de los folios $26 r-27 v, 32 v-36 r$ (que coincide con el final de la segunda jornada) y 48v-51r, con mínimas intervenciones en los folios 28v y 29r (solamente unos versos en cada caso). La alternancia en algunos folios de las dos manos, junto con la mínima intervención del segundo copista, invita a pensar que éste sólo sirvió de apoyo al amanuense principal, sustituyéndolo en momentos puntuales, y también descarta la posibilidad de que el segundo copista simplemente hubiera sustituido folios deteriorados. Sabemos que Ortiz sí que entregó originales de comedias a Juan Bautista Valenciano, pues el autógrafo de la comedia lopesca El desdén vengado es uno de los manuscritos vendidos en $1620 .^{44}$ Sin embargo, no es el caso del manuscrito de La esclava del cielo, Santa Engracia. Resulta difícil explicar por qué es una copia si se trata de la comedia adquirida directamente al dramaturgo que la compuso. Ante la ausencia de más datos, es imposible abandonar el campo de la hipótesis. Tal vez fue Claramonte mismo quien encargó una copia de su borrador autógrafo y fue ésta la que vendió como «original» a Ortiz, ${ }^{45}$ o quizá simplemente se trata de una copia sacada por motivos que desconocemos poco después de que Ortiz adquiriera la comedia. Por desgracia, se trata de un problema irresoluble con la información de la que disponemos actualmente.

En todo caso, las noticias que tenemos acerca de la actividad de Claramonte y Ortiz hacia 1619-1620 suponen un indicio importante a favor de la veracidad

44. Reyes Peña (1997: 468).

45. Era posible que un dramaturgo sacara copias de una obra suya antes de entregar el original a una compañía. Sabemos, por ejemplo, que en 1602 Agustín Castellanos vendió copias diferentes de una misma comedia a dos compañías; véase San Román (1935: 62). Falta, además, un estudio en conjunto y pormenorizado de los testimonios manuscritos del teatro de Claramonte. Por ejemplo, se ha considerado autógrafo el texto del auto sacramental El horno de Constantinopla, sin que se haya justificado adecuadamente. Por su par- te, Simón Díaz (1970: VIII, 520-521) considera también como posibles autógrafos los manuscritos de El dote del Rosario, El secreto en la mujer y El valiente negro en Flandes. Sin embargo, un rápido cotejo de los cuatro manuscritos citados revela que cada uno presenta caligrafías pertenecientes a manos distintas. Quizá en un futuro cercano el proyecto de Manos Teatrales que dirige la profesora Margaret R. Greer, dedicado a la identificación de copistas teatrales del período áureo, permita aclarar este aspecto de la bibliografía teatral de Claramonte. 
de la afirmación de que Ortiz adquirió la comedia directamente del dramaturgo murciano, como declaró al venderla a Juan Bautista Valenciano. Todo apunta a que Ortiz probablemente compró La esclava del cielo, Santa Engracia entre finales de mayo de 1619 (cuando acudió a representar a Sevilla para el Corpus) y noviembre de ese mismo año (fecha de la licencia de representación). Claramonte se había retirado del teatro profesional hacia 1616 para trasladarse a vivir a Sevilla, ciudad donde al parecer residió ininterrumpidamente hasta que regresó a Madrid en 1623, mientras que Ortiz acudió por primera vez a la capital hispalense al frente de su propia formación en la mencionada temporada teatral de 1619. Es verosímil pensar que Ortiz adquiriría la obra de Claramonte en algún momento de ese año, cuando autor y dramaturgo coincidieron en Sevilla: la licencia hispalense de noviembre podría corresponder al estreno de la obra en la misma ciudad donde residía el dramaturgo que la había compuesto. De hecho, sabemos que Andrés de Claramonte mantuvo contactos profesionales con la formación en 1620 tras el traspaso de titularidad a Juan Bautista Valenciano, pues a finales de julio de ese año la formación representó la comedia de Claramonte San Onofre o el rey de los desiertos, ${ }^{46}$ y en el manuscrito de La infelice Dorotea que se conserva con fecha de 1620 se indica que la obra se había escrito para la compañía de Juan Bautista Valenciano. ${ }^{47}$

Aunque el manuscrito carece de cualquier atribución de autoría en forma de firma o rúbrica, encontramos, en la despedida de la comedia, una referencia al pseudónimo literario del dramaturgo que compuso la obra. Esta referencia tampoco está exenta de problemas, pues el verso original está tachado por otra mano, haciendo muy difícil la lectura de la primera redacción, y se ha sustituido el pseudónimo del dramaturgo. Así, la versión original posiblemente leyó «ansí Clarindo le da / fin a La esclava del cielo", mientras que en la nueva redacción del verso se lee «ansí Lisardo le da / fin a La esclava del cielo» (fol. 56v). ${ }^{48}$ Claramonte empezó a utilizar el nombre poético de Clarindo al menos desde 1617, cuando lo empleó en su Fracmento a la Purísima Concepción, y un personaje con este nombre aparece en varias de las comedias que escribió por esos años. ${ }^{49} \mathrm{Si}$ el verso fuera completamente legible, tendríamos aquí una prueba importante a favor de la autoría de Claramonte. Baste por el momento como otro indicio en

46. Tenemos constancia de que la comedia se representó durante varios días y de que al final de la representación que se hizo el 23 de julio en el Coliseo de Sevilla la vela de una de las apariencias provocó un enorme incendio. Sentaurens (1984: 309-310 y 347), al dar cuenta de la noticia, afirmó que fue la compañía de Ortiz la que estaba representando la obra, aunque sabemos que el traspaso de titularidad entre Ortiz y Juan Bautista Valenciano había tenido lugar unas dos semanas antes del inci- dente. ¿Adquirió Juan Bautista Valenciano esta comedia después de hacerse con la titularidad de la formación o ya pertenecía al repertorio de Ortiz, aunque no conste entre las comedias que vendió a su colega el 6 de julio?

47. Claramonte (1987: 77).

48. Modernizo la ortografía y la puntuación de todas las citas de la comedia y sigo la numeración en lápiz presente en el manuscrito.

49. Véase la «Introducción» de Rodríguez López-Vázquez a Claramonte (1991b: 64). 
apoyo de la autoría de este dramaturgo junto con las atribuciones hechas en la documentación de la época.

Respecto al pseudónimo de Lisardo, la crítica no se ha puesto de acuerdo respecto al dramaturgo al que encubre este sobrenombre poético. Claude E. Anibal abogó por identificar el pseudónimo de Lisardo con Mira de Amescua, ${ }^{50}$ mientras que Cotarelo rechazó esta hipótesis y pensó (creo que sin demasiado fundamento) que se trataba en realidad de uno de los pseudónimos empleados por Lope de Vega, aunque también señaló que, como sobrenombre lírico, se asocia con personas tan dispares como don Luis de Vargas, Guillén de Castro, Luis de Góngora o el Duque de Sessa. ${ }^{51}$ La sustitución del pseudónimo original por «Lisardo" parece responder a un deseo de actualizar la despedida de la comedia (facilitado por el hecho de que ambos nombres tienen el mismo número de sílabas), atribuyéndola a otro dramaturgo, quizá más reconocido por el público en el momento en el que se llevó a cabo el cambio. Si efectivamente quien escribió «Lisardo» en el manuscrito estaba pensando en Mira de Amescua, la mejor forma de descartar la posibilidad de que fuera este dramaturgo quien escribió $L a$ esclava del cielo y de confirmar la autoría de Claramonte es acudiendo al esquema métrico de la obra, que se resume en el siguiente cuadro:

\begin{tabular}{c|l|c|c}
\hline Pasajes & Estrofa & Versos & Porcentaje \\
\hline 12 & Romance & 1.844 & $51,7 \%$ \\
\hline 5 & Décimas & 450 & $12,6 \%$ \\
\hline 3 & Quintillas & 275 & $7,7 \%$ \\
\hline 3 & Octavas reales & 250 & $7 \%$ \\
\hline 2 & Silva & 227 & $6,4 \%$ \\
\hline 4 & Redondillas & 218 & $6,1 \%$ \\
\hline 1 & Romancillo & 172 & $4,8 \%$ \\
\hline 1 & Sexteto-lira & 90 & $2,5 \%$ \\
\hline 1 & Soneto & 14 & $0,4 \%$ \\
\hline 1 & Cancioncilla & 14 & $0,4 \%$ \\
\hline & Octosílabos sueltos & 12 & $0,3 \%$ \\
\cline { 2 - 4 } & Total & 3.566 & $99,9 \%$ \\
\hline
\end{tabular}

Las estrofas de comienzo y finalización de las tres jornadas son, respectivamente: octavas reales-romance; silva-romance; décimas-romance.

50. Véase el capítulo titulado «Lisardo. Mira de Amescua’s pseudonym» en Amescua (1925: 124-190).

51. Véase la «Introducción» de Cotarelo y Mori a
Vega (1913-1930: 3, VIII-XII; y 8, XLII-XLIV).

Cabe insistir en que estos otros casos mencionados por Cotarelo se refieren a pseudónimos empleados principalmente en obras líricas, no dramáticas. 
Que Mira de Amescua no puede ser el autor de La esclava del cielo lo corrobora el cotejo de la métrica de esta comedia con la versificación que presentan las comedias del dramaturgo andaluz. ${ }^{52}$ Basta señalar, por ejemplo, que el porcentaje de romance sólo supera el 50\% en Mira a partir de 1630, fluctuando entre el $10 \%$ y el $30 \%$ alrededor de 1619 , mientras que el porcentaje de redondillas sólo se sitúa por debajo del 10\% en dos comedias tempranas, rondando entre el 50\% y el $60 \%$ hacia 1619. Las quintillas, por su parte, prácticamente desaparecen de las comedias de Mira hacia 1616. Estas grandes divergencias entre los usos métricos de Mira y la versificación de la comedia que nos ocupa son suficientes para confirmar que La esclava del cielo no salió de la pluma de Mira de Amescua.

En cambio, la versificación se ajusta en lo general a la práctica de Claramonte, hoy bien conocida gracias a Ma del Carmen Hernández Valdés y Alfredo Rodríguez López-Vázquez. ${ }^{53}$ En primer lugar, sobresale la extensión de la comedia, con más de 3.500 versos. Solamente conocemos tres comedias de Claramonte que sobrepasen los tres mil versos (aunque varias de las obras del escritor murciano han llegado a nosotros en un estado textual visiblemente deturpado y es posible que presenten un texto acortado respecto al original), siendo La católica princesa Leopolda la obra más extensa con sus 3.302 versos.

Si pasamos a considerar las diferentes formas métricas, encontramos que no divergen de la práctica de Claramonte: el romance es la forma predominante en la comedia, con un porcentaje total que sobrepasa el $50 \%$, situándose por encima del máximo uso de romance que se encuentra en otros dramaturgos contemporáneos, como Lope de Vega, Tirso de Molina o el citado Mira de Amescua, un rasgo característico de Claramonte, como señala Rodríguez LópezVázquez. ${ }^{54}$ Este porcentaje se sitúa más cerca del porcentaje máximo de romance (61\%, con la excepción de la dudosa De los méritos de amor, con un 87\%) que del mínimo (21\%) en la producción de Claramonte. Es igualmente llamativo el bajo porcentaje de redondillas usadas en la comedia, apenas un 6\%, con lo que queda relegada a la quinta forma métrica en importancia de la comedia. En general Claramonte emplea la redondilla con frecuencia y en varias obras suele ser la segunda estrofa en importancia, aunque el uso de esta estrofa fluctúa bastante en el conjunto de la producción del dramaturgo murciano, con un máximo de $34,4 \%$, pero también con seis comedias en las que no alcanzan el $10 \%$.

52. Para los usos métricos de Mira de Amescua, véase Williamsen (1977).

53. Véase a este respecto el apartado que dedica Hernández Valcárcel a la métrica y el estilo del dramaturgo murciano en su «Introducción biográfica y crítica» a Claramonte (1984: 100-109). También debe consultarse el breve capítulo que Rodríguez LópezVázquez (1987: 187-191) ha dedicado a la cuestión, así como las distintas aportaciones al estudio de los usos métricos del dramaturgo y su evolución cronológica que incluye en las diversas ediciones críticas de las obras del murciano mencionadas en nota anteriormente y recopiladas en la bibliografía final. Todas las referencias que siguen a la métrica de diversas comedias de Claramonte están tomadas de estos trabajos.

54. Véase la "Introducción» de Rodríguez López-Vázquez a Claramonte (2000: 49). 
Asimismo, es de destacar el bajo porcentaje de quintillas, un 7,7\%, una forma métrica preferida en la primera etapa de la Comedia Nueva y que sufre una transformación extrema en la práctica versificadora del dramaturgo murciano. Claramonte la emplea como estrofa principal en varias comedias tempranas, llegando a superar en La católica princesa Leopolda el 50\% del total, para luego reducirla a su mínima expresión en otras (De lo vivo a lo pintado sólo tiene un $2 \%$ de quintillas) o incluso a eliminarla por completo (como sucede en comedias como De Alcalá a Madrid, De lo vivo a lo pintado o El valiente negro en Flandes). La esclava del cielo, por tanto, se acercaría a este segundo grupo de comedias, en las que la quintilla tiene una presencia menor. La décima, una forma métrica empleada por Claramonte en todas sus comedias, ocupa el segundo lugar en importancia en La esclava del cielo, al igual que sucede en otras obras del dramaturgo murciano, como De Alcalá a Madrid y De lo vivo a lo pintado, con un $13,2 \%$ y un $21,4 \%$ respectivamente. El $12,6 \%$ de la comedia que nos ocupa presenta un porcentaje intermedio en relación con el resto de la producción de Claramonte, en la que se emplea con un mínimo del 1\% (La católica princesa Leopolda) y un máximo del $21,4 \%$ (De lo vivo a lo pintado).

Cabe destacar también la presencia de silvas y de sextetos-silva. Claramonte emplea la forma de los sextetos-silva en trece de sus comedias, con porcentajes que se sitúan entre el 0,5\% y 5\%, por lo que el porcentaje de La esclava del cielo ocupa un lugar intermedio. Por su lado, la silva, una forma habitual y realmente prometeica en las comedias de Claramonte, se sitúa por debajo de los límites máximos empleados por el murciano: El gran rey de los desiertos presenta un 9,3\%, San Carlos un 9,23\% y De lo vivo a lo pintado y La infelice Dorotea, un 8\%. Respecto a las octavas reales, el $7 \%$ de La esclava del cielo se ajusta bastante bien a la media de Claramonte, cuya producción comprende cinco comedias con porcentajes entre el 5\% y el 13\% (otras nueve comedias con octavas presentan porcentajes en torno al $5 \%$ o ligeramente inferiores). Sobresale asimismo la presencia de un soneto - forma métrica que sólo aparece en otras seis comedias de Claramonte- , cuyos tercetos riman CDC DCD (como la mayoría de los sonetos de este dramaturgo). Por último, ocho comedias de Claramonte (ninguna de ellas tempranas) presentan la forma estrófica del romancillo, también utilizada en La esclava del cielo.

Al cotejar estos datos con la evolución versificadora del dramaturgo murciano que ha propuesto Rodríguez López-Vázquez, la métrica de La esclava del cielo se ajusta sin estridencias a la dramaturgia de Claramonte. Así, uno de los rasgos característicos de la versificación del murciano consiste en un incremento en el empleo del romance más acusado y precoz que en otros dramaturgos coetáneos. El romance, además, crece en detrimento de la redondilla y especialmente de la quintilla, que pasa de prevalecer en algunas de sus primeras comedias a desaparecer en la etapa final de su producción. Como resultado del cotejo del desarrollo en el uso de estas tres formas métricas con las fechas en las que se compusieron o representaron varias de sus comedias, Rodríguez López-Vázquez ha delimitado 
tres grandes etapas en la evolución métrica de Claramonte: «Una primera etapa, seguramente anterior a 1610, en que la suma redondilla-quintilla pasa del 45 $\%$ y el romance no llega al $30 \%$ [...]; una segunda época en la que la suma de quintillas-redondillas es sensiblemente igual al romance, fluctuando ambos conjuntos en torno al $40 \%$ [...], y una última época, más o menos dilatada, en la que el romance tiene un porcentaje superior en un $15 \%$ a la suma de redondilla y quintilla». 55

La esclava del cielo se situaría a medio camino entre la segunda y la tercera época de Claramonte. Por un lado, el romance ocupa en torno al 50\% del total de la comedia y es perceptible un descenso significativo del uso de la redondilla y la quintilla (aunque sin que llegue a desaparecer esta última forma estrófica), pues en conjunto apenas rebasan el 14\%. Al mismo tiempo, la presencia de un soneto en la comedia indicaría que se trata de una obra de transición, puesto que este tipo de composición poética no aparece en ninguna comedia de la última época. ${ }^{56} \mathrm{Si}$ atendemos a los porcentajes de las principales formas métricas de comedias de Claramonte que Rodríguez López-Vázquez sitúa en esta tercera época de producción, observamos que La esclava del cielo encaja bastante bien, especialmente en comparación, por ejemplo, con la comedia De Alcalá a Madrid:

\begin{tabular}{l|c|c|c|c}
\cline { 2 - 5 } & Romance & Redondillas & Quintillas & Décimas \\
\hline San Onofre & $38 \%$ & $26 \%$ & $2 \%$ & $4,3 \%$ \\
\hline De lo vivo a lo pintado & $46,6 \%$ & $17,8 \%$ & $2 \%$ & $21,4 \%$ \\
\hline De Alcalá a Madrid & $52 \%$ & $9,2 \%$ & $0 \%$ & $13,2 \%$ \\
\hline Dineros son calidad & $54 \%$ & $24,2 \%$ & $1,8 \%$ & $13,9 \%$ \\
\hline El valiente negro en Flandes & $61 \%$ & $18,5 \%$ & $0 \%$ & $4,2 \%$ \\
\hline
\end{tabular}

Rodríguez López-Vázquez sitúa el segundo período de la producción de Claramonte en torno a 1615-1620, aunque no delimita la tercera época «más o menos dilatada» en el estilo métrico del dramaturgo, la cual abarcaría aproximadamente el período de 1620-1626. Si La esclava del cielo es efectivamente obra de Claramonte, podría datarse de forma tentativa un poco antes de 1619, cuando posiblemente fue estrenada, lo que encajaría con su condición de obra de transición entre los usos métricos de Claramonte dominantes durante la segunda mitad de la década de 1610 y los que caracterizan sus comedias más tardías.

Otro indicio en apoyo de la autoría de Claramonte lo constituye el seseo, un rasgo característico del lenguaje de dramaturgo, como ya puso de manifies-

55. Véase la «Introducción» de Rodríguez López-Vázquez a Claramonte (1984: 50). 56. Idem: 51. 
to Leavitt, ${ }^{57}$ y del que se encuentran varios ejemplos en su producción. En La esclava del cielo hay un caso de seseo en posición de rima, concretamente en el folio 34r, donde se hace rimar «dioses» con «voces». Existen otros casos de seseo en el manuscrito, aunque podrían pertenecer al copista y no necesariamente al dramaturgo pues no se encuentran en posición de rima.

Para terminar, señalaré que varios elementos de la construcción dramática de La esclava del cielo responden a los rasgos generales de la dramaturgia de Claramonte. Aunque este aspecto merece un estudio más pormenorizado, aquí sólo ofreceré unos apuntes generales, pero significativos. La esclava del cielo, Santa Engracia es una comedia hagiográfica al uso, que dramatiza la pasión y martirio, en la Zaragoza de principios del siglo IV, de Santa Engracia y sus acompańantes a manos del prefecto Daciano. Su leyenda era bien conocida a principios del siglo XVII y, por ejemplo, se recoge en diversos Flos sanctorum de la época. En la versión dramatizada en La esclava del cielo, Engracia es una princesa portuguesa cortejada en palacio por diversos señores europeos. Después de que el Esposo celestial se le aparezca y la bautice, éste ordena a Engracia que se case con Delfino, príncipe francés que se cuenta entre los pretendientes a su mano. Pese a la inicial resistencia del padre de Engracia, que persigue a los cristianos, el rey portugués termina por ceder y la princesa marcha acompańada por su primo Lupercio - también convertido tras una aparición-y otros cristianos a Francia, mientras que Delfino hace lo mismo por un camino diferente. Al llegar a Zaragoza, Engracia se enfrenta con el adelantado Daciano, cruel perseguidor de cristianos. Después de que ella rechace sus amores y de que sea traicionada por una de las damas que la acompańan, Engracia y el resto de cristianos son apresados. Lupercio es descabezado y Engracia muere poco después clavada en la cruz y en brazos del Esposo celestial, mientras que Delfino llega a Zaragoza justo a tiempo para ver fallecer a su prometida y promete morir abrazado a ella.

La esclava del cielo pertenece, por lo tanto, al género del drama religioso hagiográfico, y en ella se dramatiza y glorifica la fe y martirio de Santa Engracia. Seis de las comedias pertenecientes con seguridad a Claramonte son de temática religiosa, siendo cuatro de ellas concretamente comedias de santos (El Tao de San Antón, Púsoseme el sol, saliome la luna, El gran rey de los desiertos, San Onofre y San Carlos), un número destacado dentro de la producción del dramaturgo, como apuntó Leavitt. ${ }^{58}$ Salvo en el caso de San Carlos, que dramatiza la vida de un santo italiano de la segunda mitad del siglo Xvi, el resto de las comedias religiosas de Claramonte transcurren en un marco espacial exótico (Egipto, Levante, Persia) y lejano en el tiempo (primeros siglos del cristianismo), elementos idóneos por su distanciamiento para desplegar los argumentos y recursos

57. Leavitt (1931: 40-42).

58. Idem: 83. 
espectaculares y de tramoya característicos del género. En el caso de La esclava del cielo, se trata de una obra situada en un marco espacial hispánico (Lisboa y Zaragoza), lo que no encontramos en ninguna otra comedia religiosa de Claramonte, aunque sí que comparte con ellas la localización cronológica en la época del primer cristianismo.

En cuanto al desarrollo de la acción dramática, La esclava del cielo presenta una estructura bastante equilibrada, lejos de los extremos de acciones paralelas e inconexas que lastran algunas comedias del murciano. Si la primera jornada presenta una acción bien trabada, en la que los personajes interactúan en el espacio único del palacio de Lisboa, con Engracia como el centro de gravedad al que tienden todos los demás, en la segunda y la tercera jornada el príncipe Delfino, junto con su criado Pandulfo, pasa a protagonizar una serie de cuadros dramáticos en los que se enfrenta con un supuesto rival amoroso, el cual resulta ser el Demonio disfrazado (otro recurso presente en diversas comedias de Claramonte), quien intenta impedir que Delfino se case con Engracia provocándole celos. Esta acción paralela no deja de estar relacionada con la trama principal y, aunque los episodios de Delfino quedan bastante desvinculados de los protagonizados por Engracia por suceder en espacios completamente diferentes (los dos personajes no se reencuentran hasta la última escena de la obra), busca introducir variedad en la trama y alternancia en el ritmo de las escenas, así como un toque de humor con las intervenciones del gracioso Pandulfo. Esta disposición contribuye a que haya un desenlace algo forzado, a la vez que espectacular, un rasgo que caracteriza varias obras del murciano: ${ }^{59}$ en el último momento hacen acto de presencia en Zaragoza tanto el rey de Portugal, padre de Engracia, como el príncipe Delfino, cuya repentina llegada a la ciudad les permite asistir en persona a la glorificación y muerte de Engracia.

La espectacularidad escenográfica, empleada profusamente por Claramonte a lo largo de su producción, está presente también en La esclava del cielo. Acabo de referirme al final espectacular que cierra la comedia, en el que se hace uso de tramoyas para que diversos personajes puedan elevarse sobre el suelo o descender de las alturas. También encontramos escenas de gran espectacularidad en las otras dos jornadas. En la primera de ellas el Esposo divino se le aparece a Engracia sentado en una gloria con ángeles y fuentes a los lados, "y encima una paloma» (fol. 4r), y tanto la gloria como los personajes se elevan y descienden por medio de tramoyas. Al final de esta jornada, el mismo Esposo aparece cual deus ex machina para proteger a Engracia bajando de los cielos «en un caballo blanco [...], como pintan a San Miguel, y una lanza en la mano» (fol. 18v). Incluso encontramos al final de la segunda jornada, cuando Engracia entra en Zaragoza, la presencia de un caballo vivo en el patio del corral, un elemento escenográfico que aparentemente gustaba emplear Claramonte, según se deduce de una referencia hecha por el embajador

59. Hernández Valcárcel (2004: 91). 
Juan Antonio de Vera y Figueroa en $1636 .^{60} \mathrm{La}$ acotación en cuestión describe la escena de la siguiente manera: «Toquen chirimías y salga por el patio Engracia en una hacanea y Drusila en otra y Artemidora de la misma suerte, llevándole la falda, y Lupercio llevándole la rienda, y los demás que pudieren de acompañamiento haciendo lo mismo; y apéense al pie del tablado» (fol. 35r).

Por último, las escenas de horror, herederas del teatro senequista y presentes en varias comedias de Claramonte, hacen su aparición también en La esclava del cielo, concretamente en el tercer acto. Primero encontramos una escena en la que el fantasma de un cristiano muerto por Lupercio, primo de Engracia, se le aparece en la cárcel "pasado el cuerpo y una daga en la garganta, y con mucha sangre» (fol. 46r). Un poco más adelante es el propio Lupercio quien es asesinado, esta vez por orden del adelantado romano Daciano, quien exhibe su cabeza «en un plato" (fol. 52v) colocado encima de una mesa. En un golpe de espectacularidad, Engracia conversa con la cabeza de su difunto primo, que responde a las preguntas de la princesa portuguesa. La obra también concluye con una escena impactante, cuando Daciano muestra al rey de Portugal, quien había acudido a Zaragoza para encontrarse con su hija, a Engracia «en una cruz, clavada por la frente y atadas las manos, con el cabello suelto» (fol. 54v), padeciendo así martirio por su fe.

En conclusión, según he tratado de demostrar, el manuscrito Ms. 15705 de la Biblioteca Nacional de España, única copia conocida de la comedia $L a$ esclava del cielo, Santa Engracia, es el mismo que perteneció al autor de comedias Cristóbal Ortiz de Villazán desde 1619 y que éste vendió a Juan Bautista Valenciano en 1620. Tras la muerte de este autor en 1624, el manuscrito pasó a manos de su viuda, Manuela Enríquez, quien se asoció entonces con su cuñado, Juan Jerónimo Valenciano, en cuyo repertorio figuraba la comedia en 1628. Las referencias explícitas en dos documentos de la época a Andrés de Claramonte como autor de esta comedia, unidas a la comprobación de que tanto la métrica de la obra como los fundamentos dramáticos de la comedia se ajustan a las características generales del estilo del murciano, confirman que nos encontramos ante una obra salida de la pluma de Claramonte. De este modo La esclava del cielo, Santa Engracia se recupera en su contexto profesional específico, el de las compañías de Ortiz y los hermanos Valenciano, y en relación con el dramaturgo que la escribió, Andrés de Claramonte.

60. La referencia se encuentra en las Essequie poetiche ovvero lamento delle muse italiane in morte del Signor Lope de Vega (Venecia, 1636), publicadas a nombre de Fabio Franchi, máscara literaria de Juan Antonio de Vera y Figueroa. En el Ragguaglio di Parnaso, incluido en dicha obra, su autor imagina cómicamente a varios dramaturgos españoles que acuden al templo de Apolo para realizar peticiones con la finalidad de erradicar de sus comedias algunos defectos. Llegado el turno de Claramonte, éste "supplica si levino dalle sue Commedie tutte le disfide che si fanno in cavalli vivi, ed in particolare le donne»; véase Vega (1989: XXI, 65). Nótese a continuación que, en el caso de La esclava del cielo, Santa Engracia, son precisamente actrices las que aparecen en monturas. 


\section{Bibliografía}

Amescua, Mira de, El arpa de David, Claude E. Anibal (ed.), Columbus, Ohio State University, 1925.

Barrera y Leirado, Cayetano Alberto de la, Catálogo bibliográfico y biográfco del teatro antiguo español, desde sus orígenes hasta mediados del siglo XVIII, Madrid, Imprenta de M. Rivadeneyra, 1860 [ed. facsímil, Madrid, Gredos, 1969].

Bolaños Donoso, Piedad, «Anales del teatro sevillano: Juan Jerónimo Valenciano y su repertorio teatral (1624-1625)", El Siglo de Oro en escena. Homenaje a Marc Vitse, Odette Gorsse y Frédéric Serralta (eds.), Toulouse, P. U. de Toulouse Le Mirail-Consejería de Educación de la Embajada de España en Francia, 2006.

Claramonte, Andrés de, La esclava del cielo, Santa Engracia, Biblioteca Nacional de España, Ms. 15705.

—, Comedias, Ma del Carmen Hernández Valcárcel (ed.), Murcia, Academia Alfonso X el Sabio, 1983.

—, Deste agua no beberé, Alfredo Rodríguez López-Vázquez (ed.), Kassel, Reichenberger, 1984.

—, Púsoseme el sol, saliome la luna, Alfredo Rodríguez López-Vázquez (ed.), Kassel, Reichenberger, 1985.

—, La infelice Dorotea, Charles Ganelin (ed.), Londres, Tamesis Books, 1987.

—, El secreto en la mujer, Alfredo Rodríguez López-Vázquez (ed.), Londres, Tamesis Books, 1991a.

—, La Estrella de Sevilla, Alfredo Rodríguez López-Vázquez (ed.), Madrid, Cátedra, $1991 b$.

-, El ataúd para el vivo y el tálamo para el muerto, Alfredo Rodríguez LópezVázquez (ed.), Madrid-Londres, Tamesis Books, 1993.

—, Dineros son calidad, Alfredo Rodríguez López-Vázquez (ed.), Kassel, Reichenberger, 2000.

—, Tan largo me lo fáis. Deste agua no beberé, Alfredo Rodríguez López-Vázquez (ed.), Madrid, Cátedra, 2008.

Esquerdo Sivera, Vicenta, «Aportación al estudio del teatro en Valencia durante el siglo XviI: actores que representaron y su contratación por el Hospital General», Boletín de la Real Academia Española, 55 (1975), 429-530.

—, «Indumentaria con la que los cómicos representaban en el siglo XviI», Boletin de la Real Academia Española, 58 (1978), 447-544.

—, «Posible autoría en las comedias representadas en Valencia entre 1601 y 1679», Revista de Literatura, 41, 81 (1979), 219-238.

Ferrer VAlls, Teresa, «Actores del siglo XviI: los hermanos Valenciano y Juan Jerónimo Almella», Scriptura. Estudios sobre el teatro del Siglo de Oro, 17 (2002), 133-159. 
—, (dir.), Diccionario biográfico de actores del teatro clásico español (DICAT), Kassel, Reichenberger, 2008.

García ReIdy, Alejandro, "Una comedia inédita de Andrés de Claramonte: San Carlos o Las dos columnas de Carlos», Criticón, 102 (2008a), 177-193.

—, «Hagiografía y militancia católica en San Carlos, nueva comedia atribuida a Andrés de Claramonte», Itinerarios. Revista de estudios lingüisticos, literarios, históricos y antropológicos, 8 (2008b), 235-253.

Granja, Agustín de la, «Un caso de amancebamiento en la compañía de Juan Jerónimo Valenciano", Comedias y comediantes. Estudios sobre el teatro clásico español, Manuel Diago y Teresa Ferrer Valls (eds.), Valencia, Universitat de València, 1991.

Hernández Valcárcel, Ma del Carmen, «Andrés de Claramonte, un hombre de teatro", Paraninfos, segundones y epígonos de la comedia del Siglo de Oro, Ignacio Arellano (coord.), Barcelona, Anthropos, 2004.

Hill, John M., «Índice general alfabético de todos los títulos de comedias de Medel del Castillo", Revue Hispanique, 75 (1929), 144-369.

Leavitt, Sturgis E., The "Estrella de Sevilla» and Claramonte, Cambridge (Mass.), Harvard University Press, 1931.

Martínez Aguilar, Miguel, «En torno a la datación de El primer conde de Flandes, de Mira de Amescua", Mira de Amescua en candelero, Agustín de la Granja y Juan Antonio Martínez Berbel (eds.), Granada, Universidad de Granada, 1996, vol. I.

MériméE, Henri, Spectacles et comédiens à Valencia (1580-1630), Toulouse-Paris, Edouard Privat-Auguste Picard, 1913.

Paz y Melia, Antonio, Catálogo de las piezas de teatro que se conservan en el Departamento de Manuscritos de la Biblioteca Nacional, Madrid, Patronato de la Biblioteca Nacional, 1934.

Pérez Pastor, Cristóbal, Nuevos datos acerca del histrionismo español en los siglos XVI y XVII. Primera serie, Madrid, Imprenta de la Revista Española, 1901.

Rennert, Hugo A., The Spanish Stage in the Time of Lope de Vega, Nueva York, The Hispanic Society of America, 1909.

Reyes Peña, Mercedes de los, "Venta de un repertorio de comedias (Sevilla, 1620)", Hispanic Essays in Honor of Frank P. Casa, Robert Lauer y H. W. Sullivan (eds.), New York, Peter Lang, 1997.

—, y Bolaños Donoso, Piedad, «Presencia de comediantes españoles en el Patio de las Arcas de Lisboa (1608-1640)", En torno al Teatro del Siglo de Oro. Actas de las Jornadas VII-VIII celebradas en Almería, Heraclia Castellón, Agustín de la Granja y Antonio Serrano (eds.), Almería, Instituto de Estudios Almerienses-Departamento de Arte y Literatura, 1992.

Rodríguez López-VÁzquez, Alfredo, Andrés de Claramonte y "El burlador de Sevilla», Kassel, Reichenberger, 1987.

Rodríguez Marín, Francisco, "Nuevas aportaciones para la historia del histrionismo español en los siglos XVI y XVII», Boletin de la Real Academia Española, 1 (1914), 60-66, 171-182 y 321-349. 
Rojas Villandrando, Agustín de, El viaje entretenido, Jean Pierre Ressot (ed.), Madrid, Castalia, 1995.

San Román, Francisco de B., Lope de Vega, los cómicos toledanos y el poeta sastre, Madrid, Imprenta Góngora, 1935.

SÁncheZ-Arjona, José, Noticias referentes a los anales del teatro en Sevilla desde Lope de Rueda hasta fines del siglo XVII, Sevilla, E. Rasco, 1898.

Sentaurens, Jean, Séville et le théâtre. De la fin du Moyen Âge à la fin du XVIIIe siècle, Burdeos, Presses Universitaires, 1984.

Shergold, Norman D., y Varey, John E., Documentos sobre los autos sacramentales en Madrid hasta 1636, Madrid, Sección de Cultura-Artes Gráficas Municipales, 1958.

Simón DíAz, José, Bibliografía de la literatura hispánica, Madrid, CSIC, 1970.

Urzáiz Tortajada, Héctor, Catálogo de autores teatrales del siglo XVII, Madrid, Fundación Universitaria Española, 2002.

Vega, Lope de, Obras de Lope de Vega, Emilio Cotarelo y Mori (ed.), Madrid, Real Academia Española, 1913-1930.

- Colección de las obras sueltas, así en prosa como en verso, Madrid, Imprenta de Antonio de Sancha, 1776-1779 [ed. facsímil, Madrid, Arco/Libros, 1989].

Williamsen, Vern G., «The Versification of Antonio Mira de Amescua's Comedias and of Some Comedias Attributed to Him», Studies in Honor of Ruth Lee Kennedy, Vern G. Williamsen y A. F. Michael Atlee (eds.), Chapell Hill, Estudios de Hispanófila, 1977. 